\title{
A Case Report on Intussception Due to Vanek's Tumour
}

\author{
Dr. Ashutosh Talwar ${ }^{1 *}$, Dr. Nitin Nagpal ${ }^{2}$, Dr. Sarita Nibhoria ${ }^{3}$, Dr. Rahul Jain ${ }^{4}$, Dr. Anshul ${ }^{5}$
}

${ }^{1}$ Assistant Professor Surgery, ${ }^{2}$ Professor \& Head Surgery, ${ }^{3}$ Professor \& Head Pathology, ${ }^{4}$ Postgraduate Resident Surgery, ${ }^{5}$ Postgraduate Resident Surgery, GGS Medical College, Faridkot 151202 Punjab, India

DOI: $10.36347 /$ sasjs.2020.v06i01.008

| Received: 20.01.2020 | Accepted: 27.01.2020 | Published: 30.01.2020

*Corresponding author: Dr. Ashutosh Talwar

\section{Abstract}

Inflammatory fibroid polyp (IFP), or Vanek's tumor, is a rare benign lesion of the gastrointestinal tract. Clinical manifestations of IFP vary based on size and location within the GI tract. Review of the literature indicates that early surgical intervention is the treatment of choice for intussusception caused by IFP. Lesions are typically reported as solitary, and resection is curative.

Keywords: Intussusceptions, inflammatory fibroid polyp, adenocarcinoma, gastrointestinal tract.

Copyright @ 2020: This is an open-access article distributed under the terms of the Creative Commons Attribution license which permits unrestricted use, distribution, and reproduction in any medium for non-commercial use (NonCommercial, or CC-BY-NC) provided the original author and source are credited.

\section{INTRODUCTION}

Intussusception is uncommon among adult patients, which accounts for only 1 to $5 \%$ of the bowel obstruction cases [1, 2]. Majority of adult intussusceptions occur due to malignancies i.e. Colon adenocarcinoma. Small bowel intussusceptions are caused by benign neoplasms, and lipoma is the most common one. The inflammatory fibroid polyp (IFP), which is a reaction condition, is a rare cause of ileal intussusception [1]. Vanek's tumor, or inflammatory fibroid polyp (IFP), is a rare lesion found throughout the gastrointestinal (GI) tract but is most commonly found in the gastric antrum [3]. Peak incidence occurs in the sixth and seventh decades of life predominantly in males [4]. Clinical manifestations of IFP ranges from abdominal pain, vomittings, intestinal obstruction, intussusception, and rarely GI bleeding [5, 6].The authors report a case of terminal ileo ilealintussusception caused by IFP in a young patient.

\section{CASE REPORT}

We present a 32-yr male presented in emergency in GGS Medical College, Faridkot with history of pain whole abdomen for 4-5days, which was sudden in onset and progressive in nature.Per abdominal examination -mild distension of whole abdomen and hyperactive bowel sounds were present.
$\mathrm{X}$ ray abdomen showed dilated small bowel loops with air fluid levels, centrally placed. Right colonic gas shadow couldn't be visualised. Ultrasound abdomen showed telescoping of bowel loops in the right hypochondrium/ lumbar region- bowel within bowel appearance with? intussception. Computed tomography of the abdomen and pelvis with oral contrast revealed ileoileal intussusception. Multiple dilated proximal small bowel loops were seen with air fluid levels - small bowel obstruction.

The patient was taken for laparotomy. OT Findings were as follows- there was ileoileal intussusception with adhesions present between the intussuscepted segment of the ileum and intussucepient segment (Fig 1). On limited manipulation of this segment intussusception was reversed and the lead point was identified. Intussception part of the ileum was covered with hot sponges and active peristalsis was confirmed without any discoloration of the gut. (Fig 2) Intraluminal mass around $10 \mathrm{~cm}$ proximal to ileoceacal junction within the healthy small intestine bowel loop, mass was adherent to intestine luminal wall, not movable with firm consistency. Incision was given at antimesentric border. On exploration pedenculated mass of $3-4 \mathrm{~cm}$ was found extending upto the muscularis mucosa (Fig 3). Wedge resection was done of the involved ileum segment and primary anastomosis was done. The specimen sent for histopathological examination which confirmed the diagnosis of inflammatory fibroid polyp. Postoperative period was uneventful. 


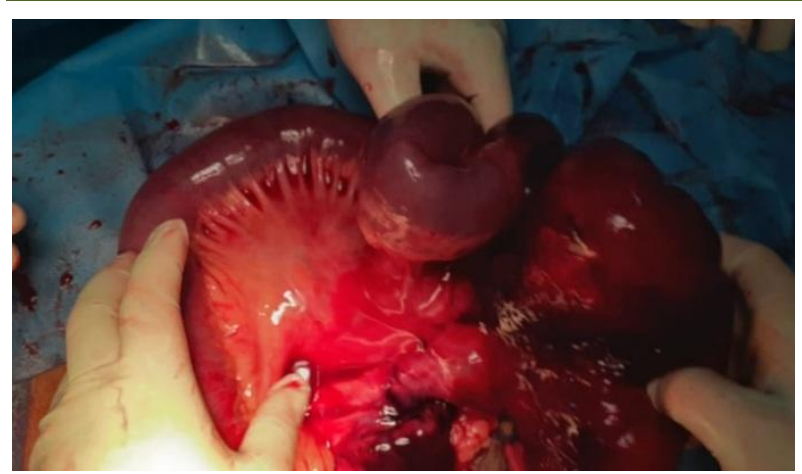

Fig-1: Showing intussception

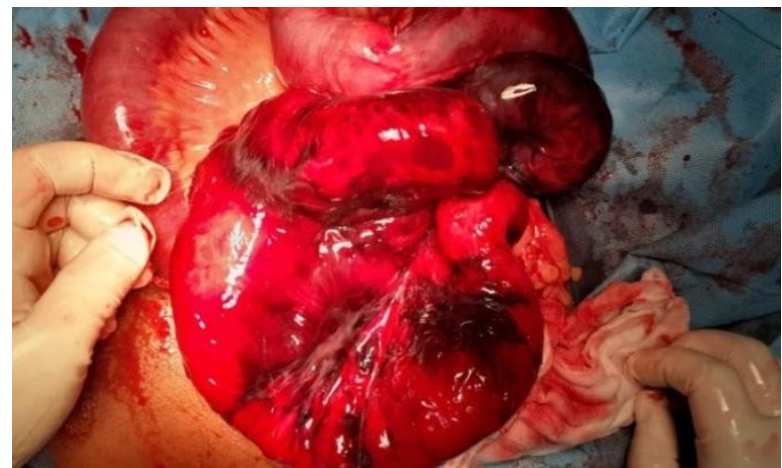

Fig-2: Gut after Hot sponge application

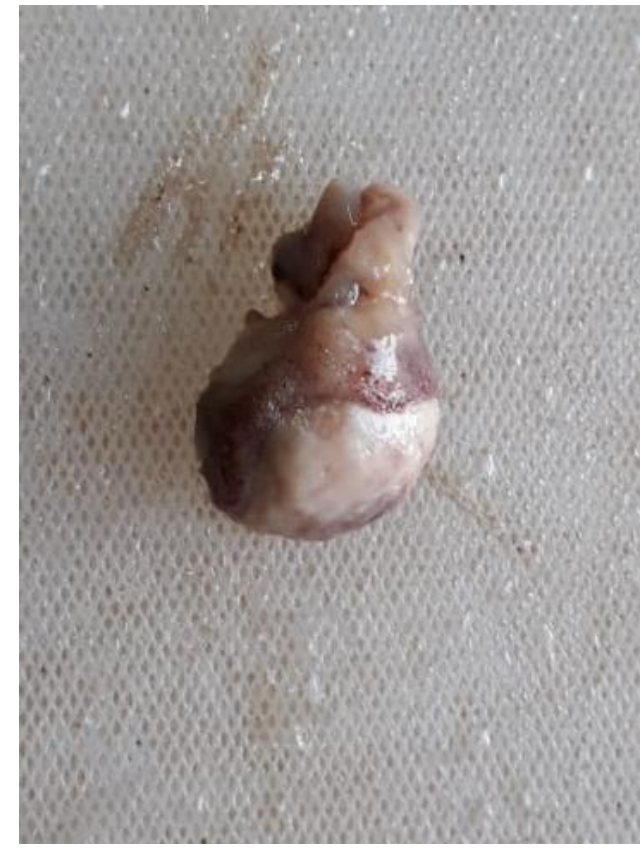

Fig-3: Cut section of polyp

\section{Histopathogical findings}

Gross Examination showed polypoidal tissue with attached part of small intestine measuring $3 \times 2.5 \times 2$ $\mathrm{cm}$. The subjacent mucosa was noted to be edematous and hyperemic. Cut section - homogenous, grey whie in colour. Upon microscopic examination- there were features of inflammatory fibroid polyp consisting of eosinophils. (Fig 4)

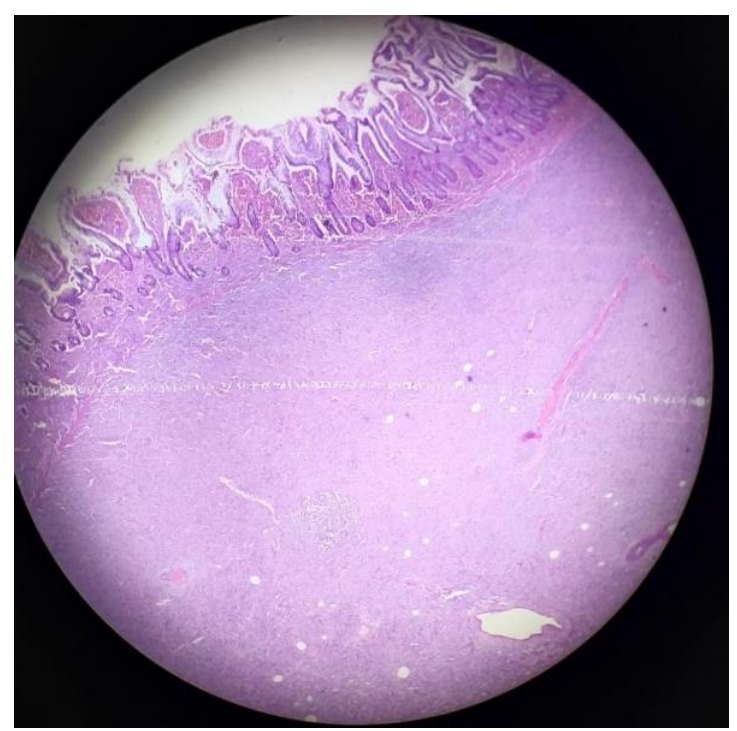

Fig-4: H\&E staining demonstrates stroma with prominent vessels and inflammatory infiltrate composed of eosinophils

\section{DISCUSSION}

IFP was first described by Vanek, in 1949, as a "gastric submucosal granuloma with eosinophilic infiltration [1]". Confusion in the literature stems from the number of different names this rare benign lesion is known by, including Vanek's tumour, eosinophilic granuloma, fibroma with eosinophlic infiltration, haemangiopericytoma and polypoid myoendothelioma[4]. Helwig and Ranier devised the generally accepted term, inflammatory fibroid polyp in 1953[5].

The fifth to seventh decade of life is the most common age at which patients present, both sexes being equally affected [4]. The most common site is the gastric antrum (60-70\%), followed by small bowel (18$20 \%$ ), colorectum (4-7\%), and far less commonly (1\%) in esophagus, duodenum, gallbladder, and appendix [2]. The polyps are typically solitary, but rare metachronous lesions have been reported in familial cases [7, 8]. Most IFPs grow intraluminally and are smaller than $4 \mathrm{~cm}$, but case reports have discussed polyps up to $20 \mathrm{~cm}$ [9]. In this case, the polyp measured $5 \mathrm{~cm}$ in greatest dimension, with the majority of the mass extending in the lumen.

Clinical manifestations depend largely on tumor location and size. Often IFPs are asymptomatic and are identified incidentally during endoscopic or surgical procedures. Epigastric pain, vomiting and bleeding are commonly observed when the lesions are located in the stomach. In contrast, patients with IFP in the small bowel are more likely to present with chronic colicky abdominal pain, small bowel obstruction, intussusception, and weight loss [1]. Such situation occurs due to the presence of intraluminal mass, which can cause a motility disorder between both intestinal segments, thus causing bowel intussusception1. GI bleeding is a rare presenting symptom, and if present, it may indicate significant ulceration or ischemia [7]. 
Xray abdomen and CT Abdomen are the imaging techniques for adults with intussusception, with sensitivity between 50 and 100\%; however, visualization of a mass within the intussusception is rare [10]. In the adult population, once intussusception is diagnosed, prompt surgical intervention is warranted to avoid complications of ischemia, necrosis, and perforation. Debate in the literature on appropriate surgical treatment for adult intussusception focuses largely on initial resection of the intussuscepted segment versus reduction followed by a more limited resection. Current recommendations favor reduction and limited resection in small bowel intussusception, but only if the bowel is easily reduced and the lead point appears grossly benign [11]. In our patient we could reduce the intussception and excise the polyp (alongwith wedge resection due to muscularis involvement).

A discussion highlighting the management, histology and features of inflammatory fibroid polyps makes surgeons aware of this uncommon disease.

\section{REFERENCES}

1. Akbulut S, Sevinc MM, Cakabay B, Bakir S, Senol A. Giant inflammatory fibroid polyp of ileum causing intussusception: a case report. Cases J. 2009;2:8616.

2. Mohamud SO, Motorwala SA, Daniel AMR, Tworek JA, Shehab TM. Giant ileal inflammatory fibroid polyp causing small bowel obstruction: a case report and review of the literature. Cases $\mathrm{J}$. 2008; $1: 341$.
3. Aguilar DB, Chablé MF, Medina FH. Pólipo fibroide inflamatório gástrico gigante. Reporte de caso y revisión de la literatura. Rev Gastroenterol Mex. 2008;73(4):239-41.

4. Gönül II, Erdem Ö, Ataoglu Ö. Inflammatory fibroid polyp of the ileum causing intussusception: A case report. Turk J Gastroenterol. 2004;15(1):5962.

5. Kan H, Suzuki H, Shinji S, Naito Z, Furukawa K, Tajiri T. A case of an inflammatory fibroid polyp of the cecum. J Nippon Med Sch. 2008;75(3):1816.

6. Kowes I, Santana S, Boente P, Corsi PR. Pólipo inflamatório fibroide: Relato de dois casos. Rev Bras Coloproct. 1994; 4(2):96-9

7. Wysocki AP, Taylor G, Windsor JA. Inflammatory fibroid polyps of the duodenum: a review of the literature. Dig Surg. 2007;24:162-8

8. Helwig EB, Ranier A. Inflammatory fibroid polyps of the stomach. Surg Gynecol Obstet. 1953;96:335-67.

9. Kong Y, Chen P. Positive solutions for periodic boundary value problem of fractional differential equation in Banach spaces. Advances in Difference Equations. 2018 Dec 1;2018(1):322.

10. Abboud B. Vanek's tumor of the small bowel in adults. World Journal of Gastroenterology: WJG. 2015 Apr 28;21(16):4802.

11. Kröner PT, Council L, Mönkemüller K. Endoscopic characterization and resection of Vanek's tumor of the duodenum. Endoscopy. 2015;47(S 01):E408-9. 